\title{
XXIV. Notes on the zeeman effect
}

\section{N.A. Kent}

To cite this article: N.A. Kent (1901) XXIV. Notes on the zeeman effect, Philosophical Magazine Series 6, 2:9, 275-279, DOI: 10.1080/14786440109462689

To link to this article: http://dx.doi.org/10.1080/14786440109462689

曲 Published online: 08 Jun 2010.

Submit your article to this journal

Џ Article views: 5

Q View related articles $₫$ 


\section{Notes on the Zeeman Effect. B $y$ N. A. KENT*}

$\mathbf{I}^{\mathrm{T}}$ T has been shown by H. M. Reese $†$ that the separation of the external components of the regular Zeeman triplet or quadruplet, as seen perpendicular to the lines of force, does not vary proportionally with the strength of the magnetic field in which the luminous source is placed. This fact was established for various zinc and cadmium lines up to a field of about 26,000 c.G.S. units.

Reese also states, in referring to certain lines in the spectrum of iron, that, "In comparing the separation of the lines between 3900 and 4450 it was at once observed that the lines could be broken up into two classes, in each of which the separation of the various lines was of the same magnitude. These two classes are identical with those for which Humphreys found that the shift due to pressure was the same. On these plates the separation is very small in all cases, owing to a weak field, and no accurate measurements were taken of the separation."

It appeared then to be a matter of no little interest to extend Reese's investigations on zinc using higher fieldstrengths; and also to make a more exhaustive investigation of the spectrum of iron and measure the separation with care. These two primary lines of study suggested others as given below.

The apparatus used was essentially that employed by Reese:-A Rowland concave grating, radius of curvature 13 feet 3 inches, of 15,000 lines per inch, fitted with the ordinary slit and camera box ; Seed's "Gilt Edge," Cramer's "Isochromatic Fast," and the International Colour Photo. Co.'s " Erythro" plates; an electromagnet giving a maximum field of 33,000 c.G.S. units for a $3 \mathrm{~mm}$. gap; as luminous source, a spark between terminals of, or containing, the metals investigated - the spark being produced by an alternating current, of 133 cycles per second passed through an adjustable impedance and through a transformer, the secondary circuit containing a condenser which discharged across the spark-gap, the Ieads to which were short thick wires (self-induction was used in the discharge circuit when it was desirous to remove the air-spectrum or sharpen the lines of the metal under investigation); and a dividing engine, whose

\footnotetext{
* From the Johns Hopkins University Circulars, vol. xx. no. 152 (May-June 1901).

$\uparrow$ Astrophy's. Journal, xii. No, 2, Sept. 1900, pp. 120-135.
} 
screw was exceedingly accurate, used to measure the Zeeman separation.

Briefly the results of the investigation are as follows:-

1. The separation of the outer components of the zinc lines $4680 \cdot 38,4722 \cdot 26,4810^{\cdot 71}$ is not proportional to the strength of field for values of the latter from 26,000 to 33,000 c.G.s. units ; that is, Reese's results for zinc are confirmed and extended.

2. Further, for iron lines chosen somewhat at random the same is true, and the lines which, in the ordinary iron spectrum, are "nebulous" in character show the least increase in Zeeman separation as the field is increased in strength ; or, in other words, the curve plotted between strength of field " $H$," and resulting separation " $\Delta \lambda$," shows the greatest droop.

3. Hence it follows that Becquerel and Deslandres *, who used a field of 35,000 c.G.s. units, were unjustified in their attempt to discover in the lines of the iron spectrum a law governing the separation. No such law as that proposed by them is apparent from measurements made on my plates of 80 lines which appeared in good form for measurement.

4. As to the pressure shift for iron:-In the spectrum of this metal 34 lines were investigated with great care. 26 . show both large pressure shift and large separation, or small pressure shift and small separntion ; while $\delta$ show either large pressure shift and small separation, or small pressure shift and large separation. Thus it cannot be said that, if a line show large pressure shift, it will show large separation; or, if small pressure shift, small separation.

5. Nickel and cobalt were investigated. No law governing the separation is apparent.

6. Preston's law that $\frac{\Delta \lambda}{\lambda^{2} \mathrm{H}}$ is constant for homologous lines of Kayser and Runge's spectroscopic series was extended. In the expression given, " $\Delta \lambda$ " represents the Zeeman separation, " $\lambda$ " the wave-length, and " $H$ " the field strength. Preston deduced this law from measurements upon the lines in the 2nd subordinate series of cadmium and magnesium, whose wave-lengths are given by putting " $n$ " equal to 3 in Kayser and Runge's formula :-

$$
\lambda^{-1}=\mathrm{A}+\mathrm{B} n^{-2}+\mathrm{C} n^{-4}
$$

where " $\lambda$ " is the wave-length, " $A$," " $B$," and " $C$ " are constants, and " $n$ " has integer values $3,4,5$, \&c. The lines

$$
\text { * Comptes Rendus, No. 129, pp. 18-24 (1898). }
$$


Table I.

Lines of Spectroscopic Series Investigated.

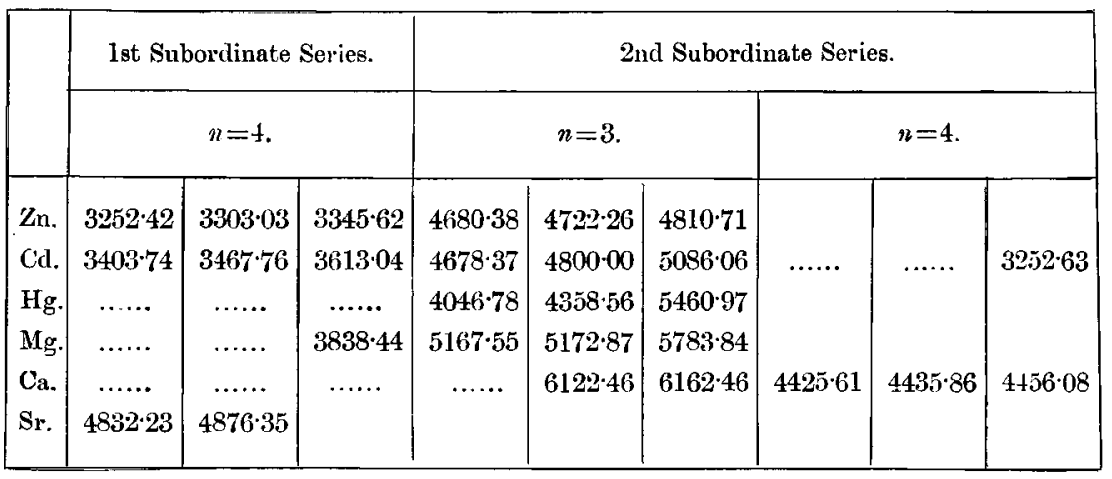

$$
\text { TABLE II. }\left({ }^{(}\right) \frac{\Delta \lambda}{\lambda^{2} \mathrm{H}} \times 10^{5} \text {. }
$$

\begin{tabular}{|c|c|c|c|c|c|c|c|c|c|c|c|c|c|}
\hline \multirow{3}{*}{ Metal. } & 1st Subor. & \multicolumn{12}{|c|}{ Znd Subordinate Series. } \\
\hline & \multirow{2}{*}{$n=4$} & \multicolumn{9}{|c|}{$n=3$} & \multirow{2}{*}{\multicolumn{3}{|c|}{$n=4$. }} \\
\hline & & \multicolumn{3}{|c|}{ Kent's results. } & \multicolumn{3}{|c|}{ Reese's $\left({ }^{2}\right)$. } & \multicolumn{3}{|c|}{ Preston's $\left({ }^{3}\right)$} & & & \\
\hline $\mathrm{Zn}$ & $\begin{array}{llll}5 \cdot 1 & 8.5 & 11 \cdot 4\end{array}$ & 16.5 & $14 \cdot 9$ & 8.9 & $17 \cdot 0$ & $15 \cdot 3$ & $11 \cdot 3$ & 17 & $14 \cdot 8$ & 9.53 & & & \\
\hline $\mathrm{Cd}$ & $5.0 \quad 8.6 \quad 11.3$ & $16 \cdot 4$ & $14 \cdot 6$ & $9 \cdot 1$ & $17 \cdot 0$ & $15 \cdot 5$ & $10 \cdot 5$ & ... & $\cdots$ & $\ldots$ & $\cdots$ & $\cdots$ & $11 \cdot 0$ \\
\hline $\mathrm{Hg}$ & $\ldots \ldots$ & $16 \cdot 7$ & $14 \cdot 7$ & $8 \cdot 7$ & $16 \cdot 7\left(^{1}\right)$ & & $10 \cdot 3$ & & & & & & \\
\hline $\mathbf{M g}$ & $11 \cdot 1$ & $16 \cdot 1$ & $14 \cdot 1$ & 90 & $16 \cdot 7$ & $14 \cdot 9$ & $10 \cdot 5$ & & & & & & \\
\hline $\mathrm{Ca}$ & $\ldots \ldots$ & $\ldots$ & {$[15 \cdot 1$} & $10 \cdot 4]$ & ...... & $\cdots$ & $\cdots$ & $\ldots$ & $\cdots$ & $\ldots$ & $4 \cdot 8$ & $8 \cdot 2$ & $11 \cdot 4$ \\
\hline $\mathrm{Sr}$ & {$\left[\begin{array}{ll}12 \cdot 8 & 12 \cdot 5\end{array}\right]$} & & & & & & & & & & & & \\
\hline $\operatorname{Mean}\left({ }^{\bar{j}}\right)$ & $\begin{array}{llll}5 \cdot 1 & 8 \cdot 6 & 11 \cdot 3\end{array}$ & $16 \cdot 4$ & $14 \cdot 6$ & $8 \cdot 8$ & 169 & $15 \cdot 2$ & $10 \cdot 7$ & 17 & $14: 8$ & $9 \cdot 5$ & $4 \cdot 8$ & $8 \cdot 2$ & $11 \cdot 2$ \\
\hline
\end{tabular}

(1) Field 26,460 C.G.s. units.

(2) Reese's values calculated from slope of curve on $H$ diagrams.

(3) Approximate mean value given by Preston for the homologous lines of $\mathrm{Zn}$, Cd, and $\mathrm{Mg}$. $\mathrm{H}=20,000$.

(4) Calculated from data given by Reese. See his article before mentioned, Astrophys. Journ. No. 2, Sept. 1900, p. 129.

$\left.{ }^{5}\right)$ Excluding strontium as it is irregular, and calcium, the measurements of which are but approximate. Note that the calcium lines agree quite well with the homologous lines in $\mathrm{Zn}, \mathrm{Cd}, \mathrm{Hg}$, and $\mathrm{Mg}$.

Phil. Mag. S. 6. Vol. 2. No. 9. Sept. 1901. 
I have investigated are given in Table I. Table II. contains in homologous positions the calculated values of $\frac{\Delta \lambda}{\lambda^{2} H}$ as obtained from measurements made on my plates together with Reese's and Preston's results. Table III. is obtained from Table II. by making corrections (fully justified *). Owing to the fact that, to obtain sufficient separation, it was necessary to use a field of over 26,000 c.G.s. units, and that consequently, as the "droop" in the $\mathrm{H}-\Delta \lambda$ curves before mentioned (see sections 1 and 2 ) is not the same for all lines, a comparison of $\frac{\Delta \lambda}{\lambda^{2} \mathrm{H}}$ is not possible until certain corrections have been made.

TABLE III. $\frac{\Delta \lambda}{\lambda^{2} \mathrm{H}} \times 10^{5}$, corrected values.

\begin{tabular}{|c|c|c|c|c|c|c|c|c|c|c|c|c|c|c|}
\hline \multicolumn{3}{|c|}{ Ist Subordinate. } & \multicolumn{12}{|c|}{ 2nd Subordinate. } \\
\hline \multirow{2}{*}{\multicolumn{3}{|c|}{$n=4$}} & \multicolumn{9}{|c|}{$n=3$. } & \multirow{2}{*}{\multicolumn{3}{|c|}{$u=4$. }} \\
\hline & & & \multicolumn{3}{|c|}{ Kent's results. } & \multicolumn{3}{|c|}{ Reese's. } & \multicolumn{3}{|c|}{ J'reston's. } & & & \\
\hline $5 \cdot 2$ & $8 \cdot 8$ & $15 \cdot 1$ & 169 & $15 \cdot 0$ & $12 \cdot 0$ & 169 & $15 \cdot 2$ & 107 & 17 & $14 \cdot 8$ & $11 \cdot 1$ & $4 \cdot 8$ & 8.4 & $14 \cdot 9$ \\
\hline Set 1 & 2 & 3 & 1 & 2 & 3 & 1 & 2 & 3 & 1 & 2 & 3 & 1 & 2 & 3 \\
\hline
\end{tabular}

Table III. shows :-

1st. That Preston's law, $\frac{\Delta \lambda}{\lambda^{2} \mathrm{H}}$ is a constant for homologous lines-established by him for the homologous lines of zinc, cadmium, and magnesium given by $n=3$ in the second subordinate series-appears to hold for the homologous lines in mercury and cadmium.

2nd. That, within the limits of accuracy of measurement, $\frac{\Delta \lambda}{\lambda^{2} \mathrm{H}}$ is the same for homologous lines given by $n=4$ in both the subordinate series for zinc, cadmitum, mercury, magnesium, and calcium. This assumes that the lines not

* The necessary corrections were determined by quite a complete study of the "droop" of homologous lines. 
investigated show values of $\frac{\Delta \lambda}{\lambda^{2} \bar{H}}$ which are the same as those investigated in each set-an assumption which is certainly not unjustifiable.

3rd. That the average value of $\frac{\Delta \lambda}{\lambda^{2} \mathrm{H}}$-obtained from Preston's, Reese's, and my determinations-for the third set in $n=3$, or $\frac{1}{3}(12+10 \cdot 7+11 \cdot 1)=11 \cdot 27$, is so related to the average value for $n=4$ (as given in the same table, III.) in the homologous sets of both subordinate series, or $\frac{1}{2}(15 \cdot 1$ $+14 \cdot 9)=15 \cdot 00$, that

$\left(\frac{\Delta \lambda}{\lambda^{2} \mathrm{H}}\right)_{n=3}:\left(\frac{\Delta \lambda}{\lambda^{2} \mathrm{H}}\right)_{n=4}:: 3: 4 ;$ as $\stackrel{1}{3}(11 \cdot 27)=3 \cdot 76$, while

$\frac{1}{4}(15 \cdot 00)=3 \cdot 75$. Thus, if we assume $\frac{\Delta \lambda}{\lambda^{2} \mathrm{H}}$ proportional to $\frac{e}{m}$ where " $e$ " is the amount of electricity carried by the particle of mass " $m$," we may say that the ratio of the charge to the mass of the particle varies directly with " $n$ " for the third set of lines in the second subordinate series where " $n$ " has either the value 3 or 4 .

(The first subordinate series shows no lines for $n=3$. The value $15^{\cdot} 1$ was averaged with $14 \cdot 9$ because of the probability of obtaining thus a more correct mean.)

4th. That there appears to be no relation between sets 1 and $2, n=4$, and 1 and $2, n=3$, or, taking total mean values, between

$$
\begin{aligned}
16 \cdot 9,15 \cdot 0 \text { for } n & =3 \text {, and } \\
5 \cdot 0,8 \cdot 6 \text { for } n & =4 .
\end{aligned}
$$

However, inasmuch as the wave-lengths of the three lines forming the spectroscopic triplet are so related to each other that, given the wave-length of one of them, those of the other two can be calculated - thus forming a connexion between the members of the triplet-we would not expect that here again a relation would appear between the first, second, and third lines of the triplet in any one series unless, indeed, it were a relation equivalent to that just mentioned, namely, the possibility of the calculation of the wave-lengths of any two lines of the triplet given that of the third. 